3. Haemorrhage with Perforated Peptic Ulcer.-Haemorrhage with perforation accounted for 3 deaths among 7 cases which presented extreme problems in treatment. In one fatal case there were two kissing duodenal ulcers-one bled and the other perforated. If this combination is suspected at operation it would be advisable to perform a short circuit and pyloric occlusion, or a partial gastrectomy if the conditions are propitious.

4. Duodenal Ulcer.-There were 3 deaths among 47 admissions with duodenal ulcers. Only one could be considered as a death during treatment for haemorrhage. Again, with the great technical difficulties of operating on a penetrating duodenal ulcer a medical bias is justifiable, except when haemorrhage is extremely brisk or repeated and if the patient is over 50 .

5. Chronic Gastric Ulcers.-The important mortality has been among the patients with chronic lesser curvature ulcers, with 7 deaths among 30 cases $(23 \%)$. Considering the age, associated complications, and chronicity of the ulcers it is doubtful if any surgeon could have achieved a substantially lower mortality if all 30 cases had had early radical operation. Bohrer (1941) gives a mortality of $26 \%$ for bleeding gastric ukers treated surgically. Nevertheless, it is in this group that timely surgery might save a few cases which would prove fatal in spite of continued transfusion. The clinical observations of grave significance are:

Thickened tortuous radial artery

Age over 50 years -5 deaths out of $18(28 \%)$

Severe pain preceding haemorrhage- 5 deaths out of 12 $(40 \%)$

Pain persisting after haemorrhage- 2 deaths out of $4(50 \%)$

Recurrent bleeding: once- 6 deaths out of $12(50 \%)$ twice -5 deaths out of $8(60 \%)$

By selecting cases which came partly or wholly within this group a reduction in mortality from bleeding chronic gastric ulcers might be effected by early operation, and this aspect is being further studied.

\section{Diagnosis Uncertain}

Sometimes one is confronted with an exsanguinated patient without a definite diagnosis, but the case will become operable only if it can be included in the indications given above. The length of history, the site of "the pain, the food relationship, and the severity of the haemorrhage are all unreliable in deciding the position and nature of the ulcer. The necessity for continued massive transfusion is not in itself sufficient reason for operation: Four patients with acute gastric ulcers had repeated severe bleeding, and needed 11,340, 6,480, 5,940, $3,780 \mathrm{c} . \mathrm{cm}$. of blood respectively, but with routine medical treatment the haemorrhage eventually stopped. A history of severe pain, especially for more than three weeks, is very suggestive of a chronic ulcer. The histories of the proved acute and chronic ulcers in this series have been analysed thus:

\begin{tabular}{|c|c|c|}
\hline Recent Pain or Discomfort & Acute Gastric Ulcer & Chronic Gastric Ulcer \\
\hline 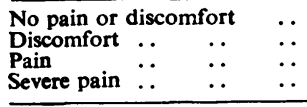 & $\begin{array}{l}8 \\
7 \\
7 \\
0\end{array}$ & $\begin{array}{r}1 \\
2 \\
15 \\
12\end{array}$ \\
\hline $\begin{array}{ccc}\text { Totals } & \ldots & \ldots\end{array}$ & 22 & 30 \\
\hline
\end{tabular}

It is legitimate in doubtful cases to try to clinch the diagnosis by screening with a thin barium emulsion or by gastroscopy. Therefore if the patient can be proved to have chronic gastric ulceration, or in exceptional circumstances chronic duodenal ulceration, and is over 50-and especially if there is thickening of the radial artery, history of severe pain, or pain persisting after admission or recurrence of haemorrhage-then operation may be advised. Nevertheless, to improve on medical treatment it is essential to have an exceptionally experienced surgeon, and a skilled anaesthetist available at short notice. If this is not forthcoming no physician need reproach himself for continuing with medical treatment.

\section{Organization}

To obtain the best possible results after haemorrhage from peptic ulcer, good organization is essential. The first requirement is an adequate blood bank. There is much to be said for nursing all cases in special dietetic wards, where the nursing staff can become very expert in all phases of treatment. The medical staff should be agreed on the routine management, and a treatment schedule in the wards is of value.

A follow-up of all proved chronic gastric ulcer patients is invaluable, for intractability can be discovered early and partial gastrectomy advised. In due course this must reflect itself favourably in the mortality rate for gastro-duodenal haemorrhage.

\section{Summary}

An analysis is presented of 171 cases of haematemesis and/or melaena personally treated by prompt feeding and liberal transfusions. There were 17 deaths $(10 \%)$.

Peptic ulceration was the probable cause in 161 cases, among which there were 14 deaths $(9 \%)$.

Early gastroscopy gave the diagnosis in nearly two-thirds of the $x$-ray-negative cases. Acute gastric ulcer is a relatively common cause of bleeding, but acute gastritis is rare.

Of the peptic ulcer subjects $30 \%$ were over 60 years of age - a much higher proportion than in previously published series.

Old age, severe complications or associated disease, and large ulcers were important factors in causing death.

Prompt feeding and liberal transfusions have decreased the incidence of recurrent bleeding.

The indications for surgery are discússed.

My thanks are due to the North-Western Blood Transfusion Depot for their liberal supplies of blood, to Dr. H. Pollak for his able assistance, and to Dr. R. Asher for his valuable suggestions.

REPERENCES

Bohrer, J. V. (1941). Ann. Surg., 114, 510.

Bohrer, J. V. (1941). Ann. Surg.,

Bulmer, E. (1927). Lancet, 2, 168. Gu's Hosp. Rep., 84. 197.

Burger, G., and Hart Price. R K (1932). St. Bart's Hosp. Rep., 65, 185.

Cullier, F. F . (1934) Lancet, 2 1271.

Hellier, F. F. (1934). Lancet, 2, 127.

Jones, F. Avery). Ibid., 2, 332 .

Miller, T. G. and Nicholson, J. T. L. (1941). Amer. J. digest. Dis., 8, 446.

Scot, T. D. W (1940). Edinb. med. J., 47, 49.

Witt: L. (1937) British Medical Journal, 1, 847.

\section{PRIMARY BRONCHIAL CARCINOMA AT THE AGE OF 4 YEARS 4 MONTHS}

BY

C. ELAINE FIELD, M.D., M.R.C.P.

First Assistant to the Children's Department, University College Hospital

AND

J. P. QUILLIAM, M.Sc., M.B., B.S.Lond.

House-physician, Children's Department, University College Hospital

Primary carcinoma of the bronchus is a condition that has attracted much attention in latter years, particularly on account of the increasing number of cases seen. Many authors have collected series of cases in attempts to discover whether this increase is absolute or only apparent. Those who hold that the rising number of cases observed is apparent invoke refinements of diagnosis-e.g., radiography, bronchoscopy, and biopsy-to support their contention; others maintain that the increase is absolute. Recently Menne and Anderson (1941) have published observations upon two series of necropsies in America, which they cite as evidence for the increasing frequency of bronchial carcinoma. In all probability there is both a real and an apparent increase in the incidence of the condition.

The growth commonly occurs in the age period generally favoured by carcinomata but with maximal incidence between 50 and 59 years, whereas the frequency of other cancers is maximal at an older age (Simons, 1937). In the age group 20-29 cases are seen from time to time; in the decade 10-19 Simons found only 6 cases in his collected figures (total 2,796). The period 0-9 years in his table shows only one case, and this in a boy aged 5 years (Hirsch and Ryerson, 1928). Beardsley (1933) reported a case of carcinoma of the lung in a female aged 10 months; and McAldowie described the clinical and necropsy findings in a boy aged $5 \frac{1}{2}$ monihs with multiple nodular growths in both lungs, but no histological examination was performed. To these 3 cases we would add the one reported below (see Table), which was histologically an anaplastic carcinoma of the bronchus in a girl aged $4 \frac{1}{3}$ years.

Beardsley quotes Nuscheler (1875) as referring to a case of carcinoma of the lung in a girl aged 7 years; and McAldowie quotes Ebermann, who found one case in his series of 76 , in 
a child under 9 years of age. These references are unobtainable and therefore cannot be included in the above series.

Both Beardsley's and Hirsch and Ryerson's cases were notable for the fact that secondary lesions were found, in the lumbar region in the former and in the tibia in the latter, before lung mischief was diagnosed. In our case the lung condition attracted immediate attention, and it was not until right pleural effusion, which was confirmed by radiographs. The effusion steadily increased, and aspiration gave $300 \mathrm{c.cm}$. of a deeply blood-stained fluid. Five further aspirations in the next seven days yielded $1,780 \mathrm{c} . \mathrm{cm}$. of a similar fluid. The last aspiration was followed by an air replacement, which considerably relieved the cough and dyspnoea.

A radiograph of the chest (Fig. 1) now showed a fluid level on the right side at about the 7 th thoracic vertebra, an artificial

Reported Cases of Carcinoma of the Lung for the Age Period 0-10 Years

\begin{tabular}{|c|c|c|c|c|c|c|}
\hline Authors & $\begin{array}{c}\text { Age } \\
\text { at First } \\
\text { Attendance }\end{array}$ & $\operatorname{Sex}$ & $\begin{array}{l}\text { Duration of } \\
\text { Illness from On- } \\
\text { set of Lung } \\
\text { Symptoms }\end{array}$ & Clinical Findings & Necropsy & Histology \\
\hline McAldowie (1876) & $5 \frac{1}{2}$ months & $\bullet$ & $5 \frac{1}{2}$ months & . & $\begin{array}{l}\text { Multiple nodules in left lung in- } \\
\text { volving pleura, with many ad- } \\
\text { hesions. Multiple nodules in } \\
\text { right lung without pleural } \\
\text { involvement. Secondaries in } \\
\text { mediastinal glands }\end{array}$ & No report \\
\hline $\begin{array}{l}\text { Hirsch and Ryerson } \\
\text { (1928) }\end{array}$ & 5 years & Male & 5 months & $\begin{array}{l}\text { Secondary tumour appeared in } \\
\text { right tibia } 16 \text { months before } \\
\text { lung symptoms }\end{array}$ & $\begin{array}{l}\text { Primary carcinoma of right lower } \\
\text { lobe. Secondaries in medi- } \\
\text { astinal glands, left lung, right } \\
\text { upper lobe, and thymus, also }\end{array}$ & $\begin{array}{l}\text { Bronchogenic } \\
\text { carcinoma }\end{array}$ \\
\hline Beardsley (1933) & 10 months & Female & 2 months & $\begin{array}{l}\text { Secondary growth in lumbar } \\
\text { region appeared one year } \\
\text { before chest symptoms }\end{array}$ & $\begin{array}{l}\text { Primary carcinoma in left lung } \\
\text { involving pleura, with adhe- } \\
\text { sions }\end{array}$ & $\begin{array}{l}\text { Adenocarcinoma } \\
\text { of left lung }\end{array}$ \\
\hline $\begin{array}{l}\text { Field and Quilliam } \\
\text { (Reported below) }\end{array}$ & $4 \frac{1}{8}$ years & Female & $2 \frac{1}{2}$ months & $\begin{array}{l}\text { Dyspnoea produced by large } \\
\text { blood-stained pleural effusion. } \\
\text { Terminally the neoplasm in- } \\
\text { volved the rib spaces and } \\
\text { anterior chest wall }\end{array}$ & $\begin{array}{l}\text { Nodules of growth in collapsed } \\
\text { right lung involving visceral } \\
\text { and parietal pleura and chest } \\
\text { wall. Metastases in bronchial, } \\
\text { mediastinal, right supraclavi- } \\
\text { cular, axillary, and coeliac axis } \\
\text { glands }\end{array}$ & $\begin{array}{l}\text { Anaplastic carci- } \\
\text { noma of bron } \\
\text { chus }\end{array}$ \\
\hline
\end{tabular}

the pre-terminal phase that secondary metastases were found clinically. The particular interest of our case lies in the age of the patient, the anaplastic nature of the growth, and the possibility of accurate diagnosis in the living.

\section{Case Report}

The child, a girl aged $4 \frac{1}{3}$ years, was admitted to hospital on Nov. 22, 1941, as an emergency case, having had an unproductive cough for 11 days and breathless attacks in the mornings for the last week. For 10 days she had had attacks of abdominal pain with nausea and vomiting. On admission the child was pale, with some cyanosis of the lips and nails and marked dyspnoea. Physical examination of the chest indicated the presence of a

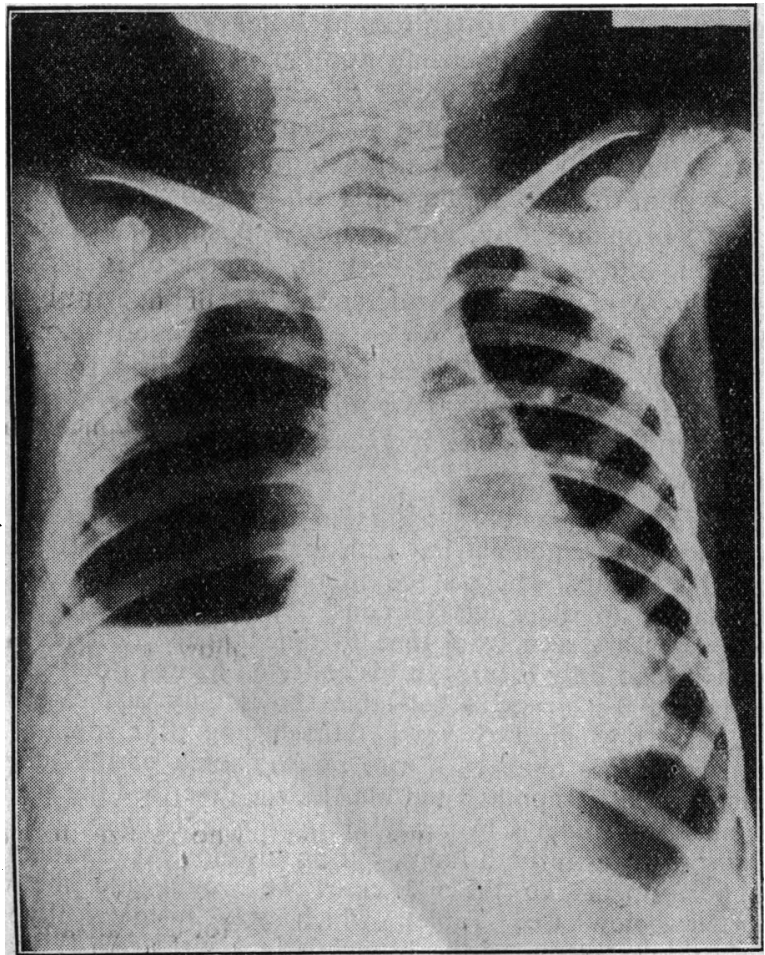

Fig. 1.-A radiograph of the chest taken after aspiration of the right side and air replacement, showing the right lung collapsed at the. hilum and nodules of growth on the parietal pleura. pneumothorax above this, the right lung collapsed at the hilum, and a nodular mass of growth at the periphery. So far no glandular enlargement had been detected and no mass felt in the abdomen.

On Dec. 13 thoracoscopy revealed the presence of numerous round, smooth, pink nodules of tissue of varying size up to $2 \mathrm{~cm}$. in diameter, widely distributed over the parietal pleura. The lung was collapsed, and was covered with thickened but smooth pleura. A biopsy specimen was taken from one of the nodules.

Report on Fluid Withdrawn.-No tubercle bacilli were found. Guinea-pig inoculation was negative for Koch's bacillus. Culture was sterile. Examination of blood-clot showed a considerable number of cells in addition to red blood cells. Mesothelial cells predominated; some contained double nuclei, and an occasional mitosis was present. The remaining cells were mostly lymphocytes. The findings were suggestive of malignancy.

Report on Portion of Pleural Tumour.-The section showed an infiltrating anaplastic carcinoma with the histological features of a bronchial carcinoma. A neuroblastoma had been considered, bu the characteristic " rosettes " were not present.

Progress.-A further aspiration and air replacement were carried out on Dec. 24 on account of respiratory embarrassment. The child's condition slowly deteriorated. The lower part of the right chest wall began to bulge and the rib spaces became filled in compared with the other side. Terminally, the ribs appeared embedded in the tumour mass. The final stage was marked by distressing bouts of coughing and dyspnoea. A week before death a fixed right supraclavicular gland was discovered; the day before death this gland was found to be further enlarged, and a gland was palpable in the right axilla. The child died on Jan. 28, 1942.

Pathological Findings.-The tuberculin patch test and the intradermal Mantoux test $1 / 100$ were negative. Repeated red blood cell counts showed no marked anaemia, and 10 days before death the $\mathrm{Hb}$ (Haldane) amounted to $94 \%$. The white cell counts showed a moderate polymorphonuclear leucocytosis, which increased terminally.

\section{Post-mortem Examination}

External.-Fairly well nourished. Right side of chest was enlarged and bulging anteriorly.

Respiratory System.- On reflecting the skin of the chest wall on the right side a firm white new growth was seen in all the intercostal spaces, infiltrating the subcutaneous tissue. It was continuous with tough white growth involving the whole of the parietal pleura, which was greatly thickened, measuring $1.5 \mathrm{~cm}$. at its maximum width. In some areas the growth was soft and breaking down into creamy fluid. The right dome of the diaphragm was pushed down and invaded and greatly thickened by the neoplasm, which appeared an the under surface as large white nodules to which the upper on the under surface as large white nodules to which the upper surface of the right lobe of the liver was firmly adherent, but there
was no infiltration. Behind the liver the growth extended downwas no infiltration. Behind the liver the growth extended downextension was formed chiefly by aortic lymph glands enlarged by growth. The heart and mediastinum were displaced to the left. 
The visceral pleura of the right lung was similarly infiltrated to a maximum thickness of $1.2 \mathrm{~cm}$., and the right lung was completely collapsed and fixed against the vertebrae. Four firm, broad, fleshy bands of the growth extended between the two layers of the pleura; they appeared like adhesions replaced with growth. On the cut surface of the right lung small areas of collapsed lung tissue were visible (Fig. 2), but the greater part consisted of white, somewhat

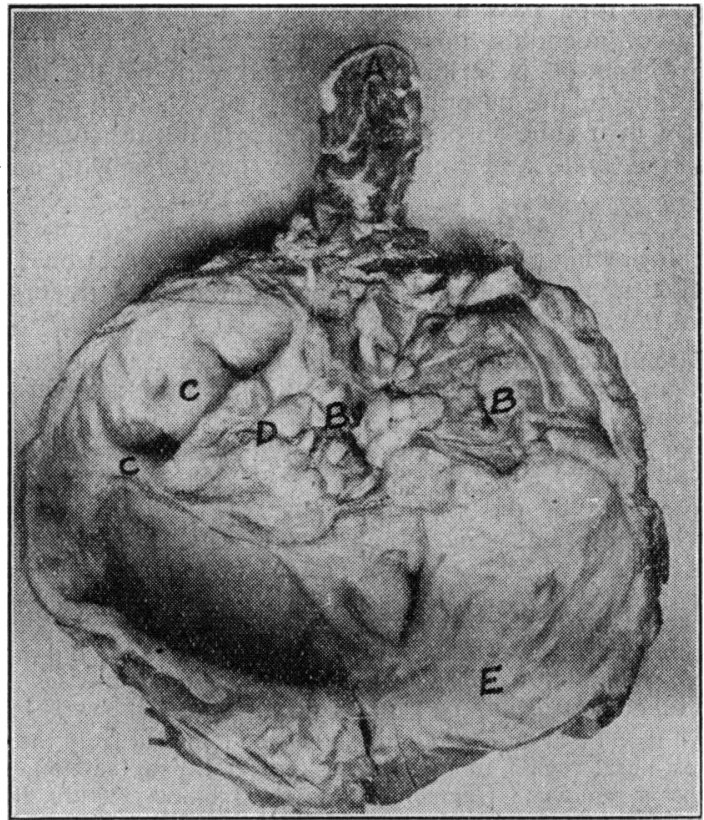

Fig. 2.-The neoplastic mass opened to show the collapsed lung containing nodules of growth, the parietal pleura greatly thickened and infiltrated, and bands of neoplastic tissue connecting the two. A, Tongue. B, Collapsed lung. C, Neoplastic bands. D, Nodules of growth. E, Parietal pleura.

soft growth. The bronchi contained muco-pus. Many bronchi were involved in the neoplasm, but this could not be seen actually arising from a bronchial wall. The hilar glands were much enlarged with white growth. The trachea and bronchi of the left lung contained muco-pus; the left hilar glands were not enlarged. Both lobes of the left lung were partly collapsed. Two small, flat, thin, round plaques were seen on the visceral pleura of the left upper lobe.

There was considerable venous engorgement in the chest and neck veins. The lumen of the oesophagus was irregularly distorted by discrete mediastinal glands enlarged by secondary neoplastic deposits. The liver showed a pale mottling; its relation to the growth has already been described. Metastases were detected in the right bronchial, all the mediastinal, the right supraclavicular, one large right axillary, and the coeliac axis lymph glands. The right adrenal gland was displaced and partly surrounded by an extension of the neoplasm beneath the diaphragm, but the capsule of the gland appeared intact, a fact confirmed microscopically. The left adrenal was normal.

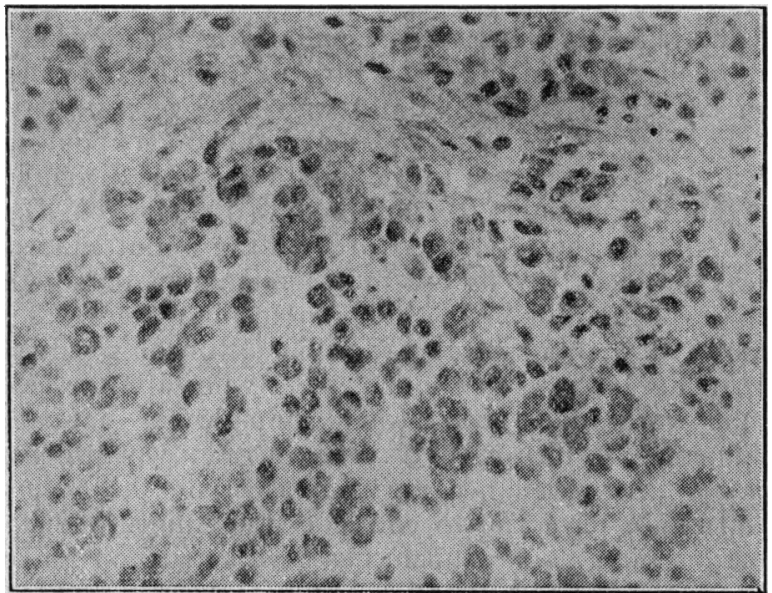

Fig. 3.-Photomicrograph showing masses of polyhedral cells and a few multinucleated giant cells.

Microscopical Examination.-Sections of the right lung and pleura and lymph glands showed a poorly differentiated carcinoma (Fig. 3) composed of masses of polyhedral cells varying in size and including multinucleated giant-cell forms in some areas. In many places where the tumour cells outlined the trabeculae of connective tissue they tended to be columnar-shaped. A large number of the cells were somewhat vacuolated; sections stained with mucicarmine gave an indefinite result. A few small areas of necrosis were present. Mitoses were not numerous.

\section{Conclusion}

The growth was an anaplastic carcinoma of the bronchus with extensive pleural involvement and metastases in the bronchial, mediastinal, right supraclavicular and axillary, and coeliac axis lymph glands.

We wish to express our thanks to Dr. W. J. Pearson for permission to publish the case and to Prof. R. S. Pilcher for performing the thoracoscopy and biopsy. We are indebted to Dr. D. M. Vaux of the E.M.S. Pathological Service for conducting the necropsy and reporting upon the fluid, the biopsy, and post-mortem material.

\section{REFERENCES}

Beardsley, J. M. (1933). Canad. med. Ass. J., 29, 257.

Hirsch, E. F., and Ryerson, E. W. (1928). Arch. Surg., Chicago, 16, 13.

Menne, F. R., and Anderson, M. W.'(1941). J. Amer. med. Ass., 117, 2215.

Simons, E. J.'(1937). Primary Carcinoma of the Lung, Chicago.

\section{NASAL INTUBATION: DANGERS AND DIFFICULTIES FROM THE RHINOLOGICAL ASPECT}

\author{
BY
}

\section{A. R. DINGLEY, F.R.C.S.}

Surgeon, Royal National Ear, Nose, and Throat Hospital

Pernasal intubation is to-day so often employed as a preliminary step in anaesthesia that it is perhaps not out of place to emphasize, from the rhinological standpoint, how necessary it is to have an adequate knowledge of the existing intranasal conditions in every case, in addition to a realization of the implications of the widely varying anatomy of the nose and of the factors limiting the safety of nasal intubation which nasal pathology can introduce. The fact that damage to the delicate structures of the nasal defensive mechanism occurs so relatively infrequently reflects great credit on the skill and care of the anaesthetist of to-day; but that harm can, and does, result cannot be denied, and serious consequences have followed the passage of a tube, either from faulty technique or from ignorance of the presence of intranasal conditions which should have debarred intubation. In other cases, less serious and often overlooked sequelae have manifested themselves later.

The nasal passages have highly important and essential physiological functions to perform: by warming, moistening, and filtering the inspired air they provide a highly specialized defensive mechanism for the protection of the respiratory tract ; they ventilate the nasal sinuses, and provide drainage for them when necessary; the patency of the Eustachian tube is maintained via their channels, and the olfactory sense is dependent on their healthy state. These nasal channels, lined by highly vascular ciliated epithelium, are often tortuous, frequently obstructed by large sharp spurs, and always intolerant of abuse.

It is unwise to regard every patient as possessing a nose which is a safe channel for the passage of a tube, or all types of case as being suitable for nasal intubation. As unwelcome complications, although infrequent, can follow this method, it is well that it should be reserved only for those cases in which it is clearly indicated and in which other methods, unattended by the same potentialities, have proved inadequate. It is not contested that nasal intubation, which owes so much to the genius of Dr. Magill, is an excellent procedure in selected cases and in the hands of those who realize the need for respecting certain contraindications. The enormous number of successful cases bear witness to its efficiency, and the following observations are merely a plea for a realization of certain difficulties and dangers which are met "with, and an attempt to help in surmounting them. The subject is approached purely from the rhinological aspect, and no particular knowledge of anaesthetics is professed. It is the oto-rhino-laryngologist, 